\title{
Finite element analysis of octagonal ring for a three component milling tool dynamometer
}

\author{
Shailendra V. Dhanal \\ Department of Mechanical Engineering, Sanjay Ghodawat Institutes, Atigre-416118, India
}

\begin{abstract}
In machine tools and tool design several parameters such as rigidity of machine tool, minimization of vibrations, increasing surface finish, optimizing the weight, etc are important. The designer should know the magnitude of cutting forces and their transmission through various components. Milling tool dynamometer uses octagonal rings along with bonded electrical strain gauges for measuring the forces in a set of co-ordinates. In this study, the three component milling tool dynamometer is designed and developed. The calibration of the dynamometer is done by applying loads at regular interval and calibration curves were obtained. The octagonal ring has been studied using finite element analysis. The results obtained showed that octagonal ring used in dynamometer measures arbitrarily applied three dimensional forces in static and dynamic conditions. It is an easy way than actual practical works which leads to save the time.
\end{abstract}

Keywords: Cutting force measurement, dynamometer, octagonal ring, Finite element analysis

\section{INTRODUCTION}

In the qualitative analysis of the metal cutting process, it is essential to determine accurately the cutting forces encountered during the cutting process. Tool dynamometer is reliable equipment for evaluating the cutting forces resolved in co-ordinate components during metal cutting operation. The cutting forces in milling must be analyzed due to the discontinuous nature of the cutting and chip geometry changing continuously. The cutting forces, temperature, vibration and acoustic emission signals occurring during cutting are the sources of information about the basic mechanics of chip formation. In dynamometers octagonal ring is designed and placed as it will deform by the force component measured. The ring must be machined identical and symmetrical to prevent cross sensitivity in measurement and they should have high quality surface. The symmetry of ring provides parallel paths for heat flow. The deformation of ring is proportional to strain on strain gauge. This deformation should not exceed extension limit of strain gauge. Many researchers have contributed for the development of ring transducers.

O'Dogherty ${ }^{1}$ developed expressions for stress, strain and deflection of circular and octagonal rings. Haci Saglam and Ali Unuvar ${ }^{5}$ developed computer linked three component strain gauge based milling tool dynamometer. Sudhir Kumar et al. ${ }^{2}$ studied a ring shaped force transducer using finite element analysis. Chen B et $a l .{ }^{3}$ studied the stress and strain distributions in a ring strain sensor, subjected a pair of pressing loadings using Finite Element Method.

In this study, octagonal ring used in three component milling tool dynamometer is analyzed using software ANSYS. The calibration readings for various loads in three directions were obtained. For these loads various strains produced were recorded. The results obtained from ANSYS were compared with the calibration results to define failure of ring at different loading conditions without any experimental work.

\section{CALIBRATION OF DYNAMOMETER}

Dynamometer can measure three perpendicular cutting force components simultaneously during milling. The dynamometer was calibrated statically for accuracy. It is convenient to use a system having linear calibration. The calibration was made in three directions thrust force, feed force and cross feed (main cutting) force and the output voltages in mv were averaged for each direction. The loads were applied at regular intervals and the strain values were recorded for each load intervals. To verify the consistency some measurements were repeated few times.

TABLE 1 shows calibration results

\begin{tabular}{|c|c|c|}
\hline $\begin{array}{c}\text { Thrust } \\
\mathrm{mv}\end{array}$ & $\begin{array}{c}\text { Cross feed } \\
\mathrm{mv}\end{array}$ & $\begin{array}{c}\text { Feed } \\
\mathrm{mv}\end{array}$ \\
\hline 9.5 & 13 & 5.5 \\
\hline 18.5 & 26 & 9.5 \\
\hline 30 & 39.5 & 15.5 \\
\hline
\end{tabular}




\begin{tabular}{|c|c|c|}
40 & 52.5 & 20.5 \\
\hline 47.5 & 65.5 & 24.5 \\
\hline 59 & 78.5 & 29.5 \\
\hline 70.5 & 92.5 & 34 \\
\hline 80 & 105.5 & 39 \\
\hline 89.5 & 117 & 44.5 \\
\hline 100 & 132 & 49.5 \\
\hline 108 & 145.5 & 54.5 \\
\hline 118.5 & 158 & 58.5 \\
\hline 131.5 & 170.5 & 63 \\
\hline 141 & 182 & 68 \\
\hline 152 & 195.5 & 73.5 \\
\hline 160.5 & 210 & 79.5 \\
\hline 169.5 & 222 & 85 \\
\hline 180 & 235 & 90 \\
\hline 189.5 & 246.5 & 95 \\
\hline & &
\end{tabular}
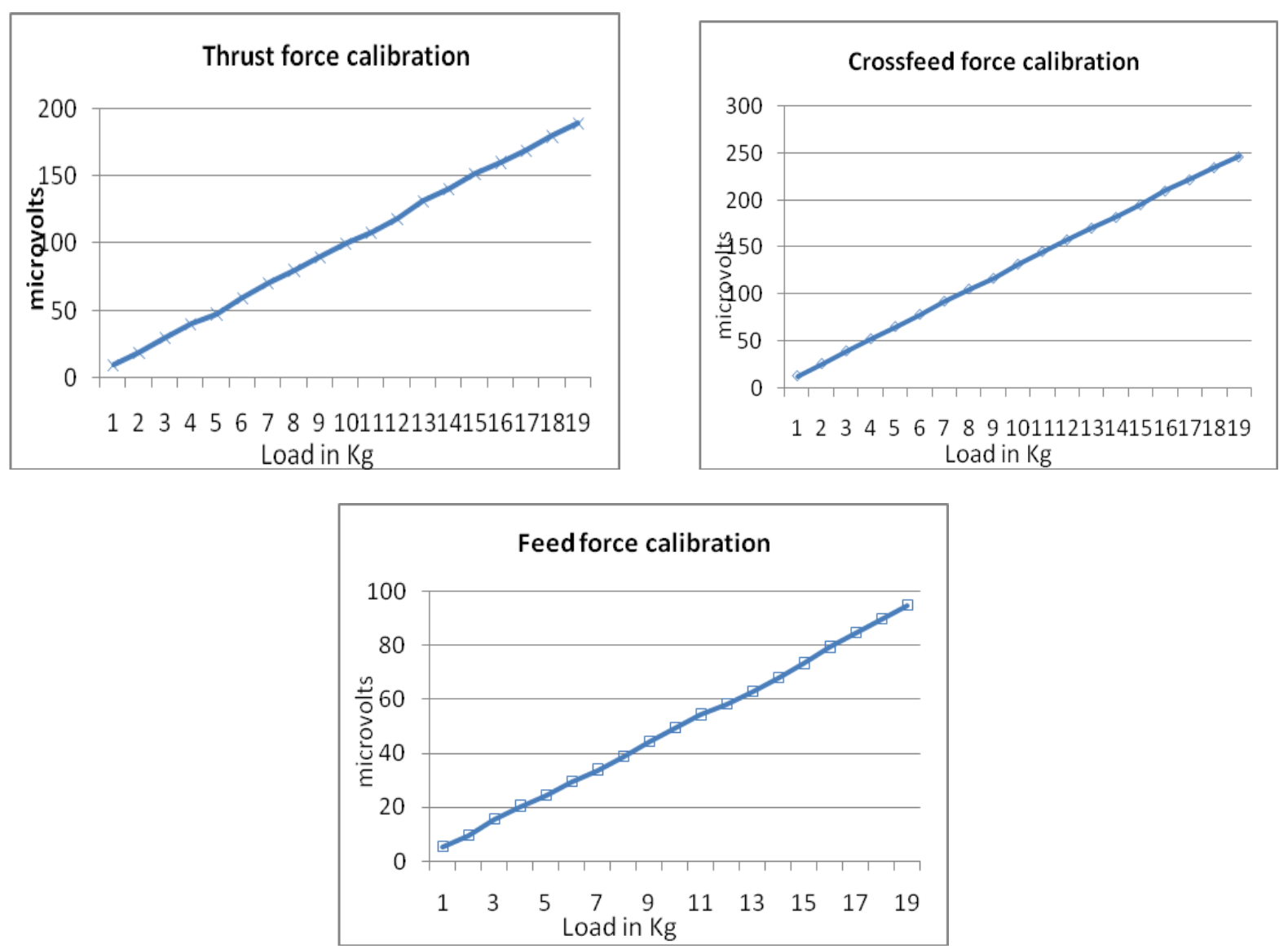

Fig. 1 Calibration curves

\section{FINITE ELEMENT ANALYSIS}

In this study, using ANSYS software first 2D model of octagonal ring was prepared by using various native commands like keypoints, circle, asba for subtract and then converted 2D into 3D model by using command vdrag. The suitable boundary conditions have been defined. The material assumed to be isotropic in nature and analysis is of linear type. The material properties for octagonal ring are mp,ex,2,0.21e6 mp,nuxy,2,0.31. Here Young's modulus is $210 \mathrm{GPa}$ and Poission ratio is 0.31 . Types of elements used in the analysis includes PLANE2, 6 nodes for structural 2D solid and SOLID 45, 8 nodes for structural 3D solid. In meshing the Octagonal ring is divided in number of finite pieces called element. Meshing is done very fine to get accurate results for particular element. One of the important thing is that meshing size is always less than the dimensions of component. 


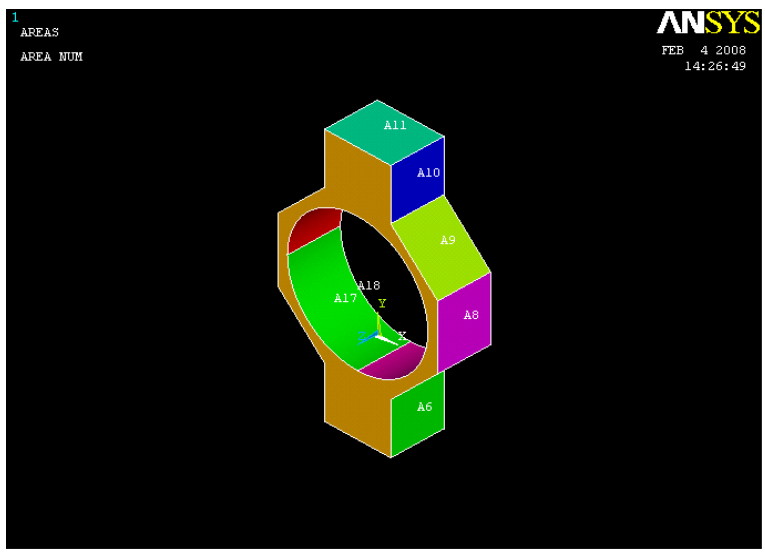

Fig.2 3D model of octagonal ring

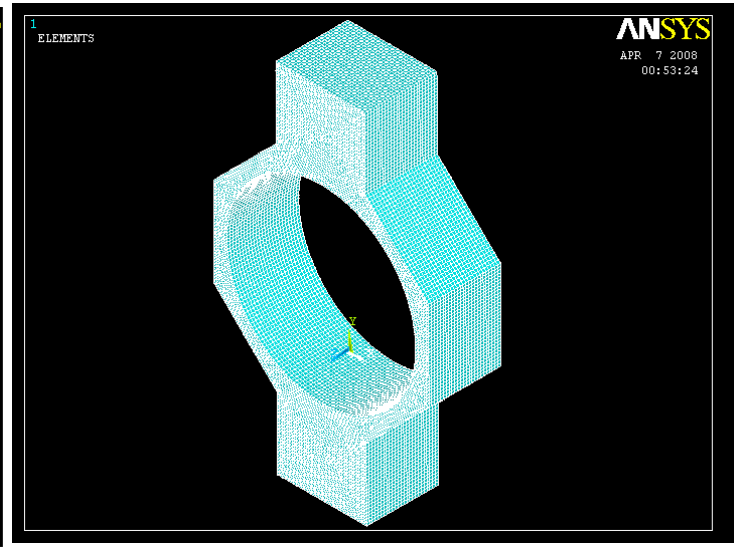

Fig.3 Meshing of octagonal ring

IV. RESULTS AND DISCUSSION

The results of finite element analysis are carried considering three loads 130, 190 and $300 \mathrm{Kg}$. The program is performed for these loads. e.g. For $130 \mathrm{Kg}$ load the results for strain in $\mathrm{X}, \mathrm{Y}, \mathrm{Z}$ directions are shown in figures. These results obtained from FEA shows approximations with the results of calibration

TABLE 2 shows the comparison between two results.

\begin{tabular}{|c|c|c|c|}
\hline Load in Kg & $\begin{array}{l}\text { Strain (X) / ANSYS } \\
\text { (microstrain) }\end{array}$ & $\begin{array}{l}\text { Strain(Y) / ANSYS } \\
\text { (microstrain) }\end{array}$ & $\begin{array}{l}\text { Strain(Z) / ANSYS } \\
\text { (microstrain) }\end{array}$ \\
\hline 130 & $0.132 / 0.126$ & $0.171 / 0.184$ & $0.70 / 0.124$ \\
\hline 300 & $0.303 / 0.314$ & $0.400 / 0.430$ & $0.150 / 0.184$ \\
\hline
\end{tabular}

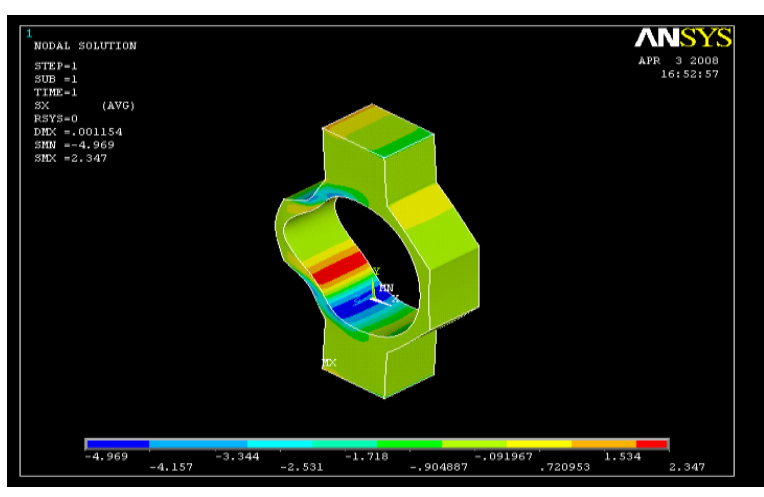

Fig.4 Stress in $\mathrm{X}$ direction

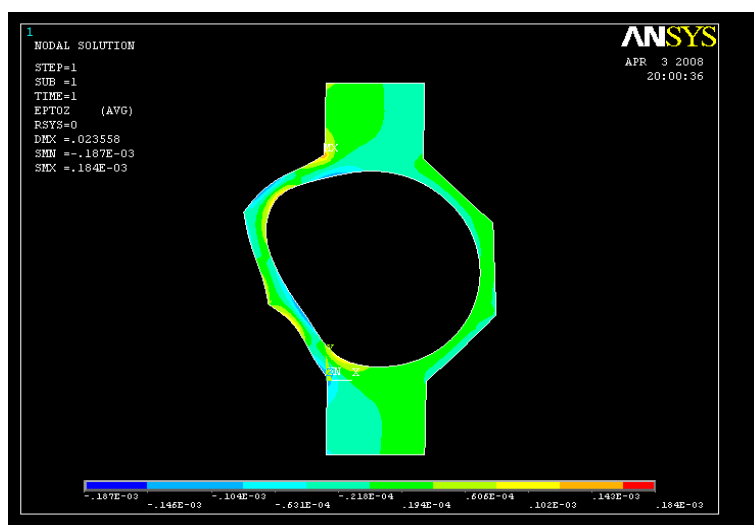

Fig.6 Strain in Y direction

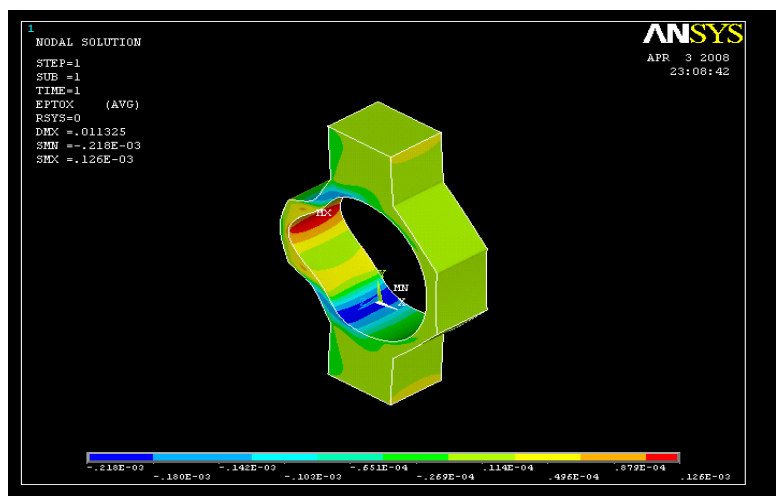

Fig.5 Strain in X-direction

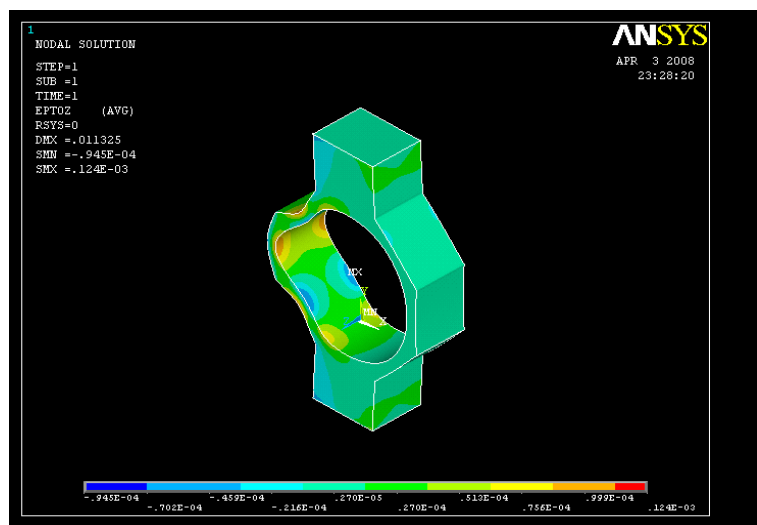

Fig.7 Strain in $\mathrm{Z}$ direction 


\section{COCLUSIONS}

1. The finite element analysis can be more advantageous and accurate method for obtaining stresses and strains in three directions of the octagonal ring for milling tool dynamometer.

2. In $\mathrm{X}$ direction the approximations are 6 to 11 microstrain, in $\mathrm{Y}$ direction 13 to 30 microstrain and in $\mathrm{Z}$ direction 34 to 54 microstrain.

3. From the comparison observed of calibrated results and FEA results, it was concluded that this analysis saves the time and efforts required for experimentation.

4. This study can be used reliably to measure cutting forces of machine tools. Tool life, tool wear and surface roughness can be determined taking cutting forces as reference.

\section{AKNOLODGEMENTS}

The author expresses his sincere thanks to Mr. D. P. Patil, Associate Professor, Padmabhooshan Vasantraodada Patil Institute of Technology, Budhgaon Sangli for his valuable guidance and support.

\section{REFERENCES}

[1] M. J. Dogherty (1996) The design of octagonal ring dynamometers. Journal of Agricultural Engineering Research, 63, 9-18

[2] Sudhir Kumar, Nabi Hasan, Harish Kumar and Anil Kumar (2011) Finite element analysis of a force transducer. Indian Journal of Science and Technology, 4(10), 1246-1247.

[3] Chen B, Wu X and Peng X (2007) Finite element analysis of ring strain sensor. Sensors and actuators A, physical 139, 66-69

[4] Madhuban Prasad, Nabi Hasan, Anil Kumar and Harish Kumar (2011) Design studies of a square ring shaped force sensor, Intl. J. Appl. Engg. Res. Dindigul, 1(4), 727-733.

[5] Haci Saglam and Ali Unuvar (2001) Three component strain gauge based milling tool dynamometer design and manufacturing. Journal of Integrated design and Process Science, 5(2), 95-102

[6] M.C. Shaw (1984), Metal Cutting Principles, Clarendon Press, Oxford. 